\title{
Editorial: Junctures in Teaching and Learning
}

Jannik Haruo Eikenaar

University of British Columbia Okanagan

DOI: $10.22329 /$ celt.v11i0.5716

$A$ s Denise Stockley notes in her "Message from the IPresident," the gateways theme of STLHE's 2017 conference works in several ways for reflecting on the Halifax-based event. Conference presentations variously attended to the theme, attendees traversed literal gateways as they journeyed among the host institutions, and this edition of Collected Essays in Learning and Teaching (CELT), an indirect product of the conference, can be seen as a kind of chronological gateway, a means of stepping back to the conference itself. Gateways imply places, and they also suggest movement: one steps through a gateway, moving from one location to another, often with no sign other than the gateway itself that any kind of distinction should exist between those locations. Gateways, then, might also be understood as markers, identifiers of junctures, and CELT, as a gateway, might identify junctures between and among spaces of learning and teaching.

Recently, I was reminded of this idea of juncture during a reading group discussion of Halualani, Mendoza and Drzewiecka's review (2009) of intercultural communication studies. There, Halualani et al. borrow Stuart Hall's deployment of juncture to "simultaneously look back and ahead" (p. 18) in reflecting on the state of the field, recognizing its overlapping terrains, and imagining its futures. It can be uncomfortable to occupy a juncture because it demands an awareness of overlapping conceptual spaces, as well as critical attention to both the spaces and their occupants. The discomfort, though, is generally productive, and Halualani et al. are careful to gesture toward the positive, productive growth that follows experiences of juncture: they emphasize that junctures are not merely critical breaks but also markers that "signal growth, change, transformation, and new ways of joining, meeting, and relating" (p. 32). This resonates in Stockley's "Message," with its suggestion of a spirit of adventure, open-mindedness, and optimism.

The reading group discussion was a rare opportunity, one that reminded me of the value in taking the time to reflect on (and then re-define) my own teaching goals, contexts, and practices, as well as the value of comparing and contrasting my approaches with those of my colleagues. These were, though, the same reminders that I have consistently enjoyed in working on this edition of CELT. The essays that follow are opportunities to reflect on our everyday educational practices, to learn about new types of assessments and assignments, and to become aware of new protocols and systems. Perhaps, like me, you will see these contributions to the journal as not only accounts of your experience as teachers and learners but also as moments of insight and guidance. If so, I hope you will share my gratitude to the authors for shaping these junctures.

The eleventh edition of CELT opens with an article from Alison Jeppesen and Brenda Joyce (Red Deer College), "Challenges and Successes: Faculty Reflections on a Teaching Development Program." Jeppesen and Joyce discuss the impact among faculty who developed self-reflective practices via a teaching development program. Next, Wallace Lockhart (University of Regina), Brad Wuetherick (Dalhousie University), and Nola Joorisity (University of Regina) report on a multi-stage research project aimed at understanding foundations for student success in 
"Exploring the Foundations for Student Success: A SoTL Journey."

This is followed by three specific examples of contributions to student success. In "Taking Social Entrepreneurship Education to the Next Level - A Teaching and Learning Project at Renaissance College (University of New Brunswick)," Thomas Mengel and Maha Tantawy (University of New Brunswick) report on improving students' engagement and satisfaction through student-centred re-design of a course about social entrepreneurship. Neil Haave, Kelly Keus, and Tonya Simpson (University of Alberta), in "A Learning Philosophy Assignment Positively Impacts Student Learning Outcomes," describe outcomes of using a learning philosophy assignment in biology and biochemistry courses to engage students in metacognition of their learning. And Clark Mathany and Jason Dodd (St. Lawrence College), in "Student-Generated Interview Podcasts: An Assignment Template," describe the delivery and outcomes of a podcast assignment, and provide a template to instructors interested in similar assignments.

Following these specific, course-based examples, Celia Popovic (York University), Mandy Frake Mistak (York University), Alison Jeppesen (Red Deer College), Cynthia Korpan (University of Victoria), Suzanne Sheffield (Dalhousie University), and Mark Weyers (Western University) summarize outcomes of an Educational Developers Caucus (EDC) working group that transformed into a full EDC Accreditation Committee in "Shoes for the Shoemaker's Children: Providing an Accreditation Process for Programs Offered by Educational Developers."

Victoria Chen (Humber College), in "Please Stop Blabbing: A Prescription for Verbal Diarrhea," then reflects on an initiative in an Active Learning Classroom and makes suggestions for facilitating greater quality, rather than quantity, of in-class contributions.

In "The Study of the First-Year Academic Experience at a Growing Liberal Arts Institution,"
Robyne Hanley-Dafoe and Cathy Bruce (Trent University) report on an 18-month, mixed-methods study of faculty, staff, and students' perspectives on first-year experiences.

Next, Gail Frost and Maureen Connolly (Brock University) discuss challenges faced by postsecondary students recovering from concussion, and offer suggestions to course instructors for accommodating recovery, in "If You Don't Mind It Does Matter: Managing the Transition from Concussion to Return to Learn in Postsecondary Education." This is followed by a reflection from Bettina Callary, Patrick Maher, Emily Root, and Jennifer Ryan (Cape Breton University). In their "Exposition of Process-Based Learning for First Year University Students," they reflect on pedagogical responsibilities, particularly in facilitating metacognitive outcomes, based on instruction of a first-year course. And, finally, Rebecca Visser and Alison B. Flynn (University of Ottawa) describe the design and delivery of an open education, organic chemistry resource, focusing on the resource's design principles rather than the course-specific content in "What Are Students' Learning and Experiences in an Online Learning Tool Designed for Cognitive and Metacognitive Skill Development?”

A final note: $C E L T$ itself has moved through a gateway, transitioning between editorial teams. Neil Haave, the outgoing Managing Editor, has been incredibly generous in offering support during the transition, and we are extremely grateful for his help and advice. On behalf of the editorial board, I would also like to thank Dianne Bateman and the rest of the STLHE executive for their support, and, of course, this edition's authors and reviewers. Trystan Carter, editorial assistant, worked tirelessly in copyediting, layout, and proofreading. In my role as Managing Editor, I have relied heavily on the other members of the editorial board, Cathi Shaw and Jordan Stouck, and I am grateful for their professionalism, patience, and positive approach to the work! 


\section{References}

Halualani, R. T., Mendoza, S.L., \& Drzewiecka (2009). "Critical" junctures in intercultural communication studies: A review. The Review of Communication, 9(1), 17-35. 